\title{
Primary care expenditures before the onset of Alzheimer's disease
}

\author{
S.M. Albert, PhD, MSc; S. Glied, PhD; H. Andrews, PhD; Y. Stern, PhD; and R. Mayeux, MD, MSc
}

\begin{abstract}
Objective: To investigate primary care expenditures in the period before diagnosis of AD. Methods: In a population-based sample of Medicare enrollees in New York City, person-level 1996 Medicare claims, summed over primary care encounters, were examined for people who developed AD in 1997 to 1998 and those who did not. Results: People who developed AD were more likely to use Medicare outpatient and ambulatory care 1 to 2 years before diagnosis. Compared with respondents who did not develop $\mathrm{AD}$, the excess cost for men was $\$ 1,167$ (85\% higher) and for women $\$ 239$ ( $26 \%$ higher). Among elderly people $\geq 75$ years in the United States, the prodromal period of AD was associated with an excess Medicare-based primary care cost of $\$ 128.5$ to $\$ 194.7$ million. Conclusion: In addition to huge costs associated with $\mathrm{AD}$ after diagnosis, prediagnosis costs are an unrecognized source of expenditures related to the disease.
\end{abstract}

NEUROLOGY 2002;59:573-578

It is unclear if people with declining cognitive abilities use primary care medical services to a greater extent than elderly people without cognitive deficits. Studies of medical care costs for older adults with early $\mathrm{AD}$ have been inconsistent, with some studies reporting increased utilization and others no difference. One study used the Mayo Clinic (Rochester, MN) database to examine an incident cohort of patients with $\mathrm{AD} 1$ year before diagnosis and 4 years after diagnosis. ${ }^{1}$ This study found no differences in inpatient or outpatient care between $\mathrm{AD}$ cases and matched control subjects in either the pre- or the postdiagnosis period. By contrast, studies of the cost of $\mathrm{AD}$ in Medicare managed care have reached the opposite conclusion..$^{2,3}$

Differences in study designs make it hard to reconcile these findings. Because of the high use of nursing home care in the Mayo Clinic study, it is possible that $\mathrm{AD}$ cases received primary care in this setting. Ambulatory and outpatient care costs associated with $\mathrm{AD}$ in regions or medical systems with less nursing home use may therefore be higher. By contrast, the managed care studies may have overestimated costs associated with AD. Because these studies did not have clinical diagnoses for ascertaining $\mathrm{AD}$ cases independently of medical claims, they may have introduced an "observation bias," in which only cases with the highest expenditures were identified. ${ }^{4}$

Additional material related to this article can be found on the Neurology Web site. Go to www.neurology.org and scroll down the Table of Contents for the August 27 issue to find the link for this article.
Although it is clear that $\mathrm{AD}$ is associated with excess nursing home and in-home assisted living expenditures, ${ }^{5-9}$ primarily captured in Medicaidreimbursed expenses, no such consensus exists for primary care in the earliest period of the disease. ${ }^{8,10-14}$ To investigate this issue, we examined primary care expenditures for older adults 1 to 2 years before they received a diagnosis of $\mathrm{AD}$ and compared their experience with that of elderly people from the same cohort who never received a diagnosis. For comparison purposes, we also include costs for prevalent AD cases in 1996.

Methods. Derivation of study sample. The Washington Heights-Inwood Columbia Aging Project (WHICAP) is a longitudinal population-based cohort, in which clinical and epidemiologic data are collected at regular intervals and vital status is continually updated. This stratified random sample was drawn from Medicare enrollment files ( $\mathrm{n}=$ 2,126) in northern Manhattan, NY, in 1992 to 1993. Sampling strata for this survey included age (65 to $74, \geq 75$ years) and race-ethnicity (Hispanic, non-Hispanic black, and non-Hispanic white). Thirty-seven systematic replicate subsamples were drawn using random starts, such that each subsample contained age and race-ethnicity groups of equal size. The response rate for the entire sample at baseline was $62 \% .^{15,16}$ Analyses comparing WHICAP participants and nonparticipants did not reveal differences in sex or race-ethnicity. ${ }^{17}$ The Columbia University/New York Presbyterian Institutional Review Board reviewed and approved the WHICAP protocol.

The derivation of subjects included in analyses is shown in figure 1. By the end of 1996, 319 (15\%) subjects were

From the Gertrude H. Sergievsky Center and Taub Institute for Research on Alzheimer's Disease and the Aging Brain; Divisions of Sociomedical Sciences and Health Policy and Management, School of Public Health; and Departments of Neurology and Psychiatry, College of Physicians and Surgeons, Columbia University, New York, NY.

Supported by federal grants AG07232 and AG08702, National Institute of Aging, and Charles S. Robertson Memorial Gift, Blanchette Hooker Rockefeller Foundation.

Received November 28, 2001. Accepted in final form April 8, 2002.

Address correspondence and reprint requests to Dr. Steven M. Albert, Gertrude H. Sergievsky Center, P\&S Box 16, PH-19, Columbia University, 630 W. 168 St., New York, NY 10032; e-mail: sma10@columbia.edu 


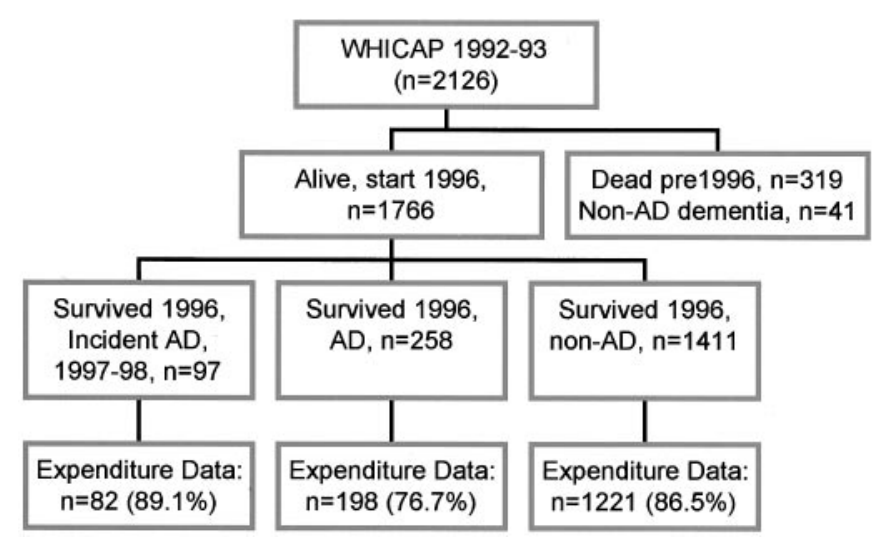

Figure 1. Expenditure study sample: Washington Heights-Inwood Columbia Aging Project (WHICAP).

known to have died. These people were excluded because we matched subjects to medical claims data beginning in January 1996 and restricted the sample to those who could have claims throughout the whole year. We also excluded 41 subjects with other forms of dementia (stroke-related dementia or dementia from focal effects of stroke; dementia secondary to metabolic, toxic, or traumatic causes; hydrocephalus; or dementia with unknown cause), though we recognize that some may be considered cases of "possible AD." We used Alzheimer's Disease and Related Disorders Association-National Institute of Neurological Disorders and Stroke criteria to identify people with probable AD, $\mathrm{AD}$ with stroke, $\mathrm{AD}$ with parkinsonian features, or $\mathrm{AD}$ with other concomitant disease.

Excluding subjects who died before follow-up or who had non-AD-related dementia left a sample of 1,766 who survived 1996. Of these subjects, 258 were diagnosed with $\mathrm{AD}$ in 1996 or earlier and were considered prevalent cases. One thousand four hundred eleven never met criteria for $\mathrm{AD}$ at any point throughout 1996 to 1998, and 97 met criteria for $\mathrm{AD}$ for the first time in either 1997 or 1998 . As incident cases were ascertained in 1997 to 1998 and we examined medical claims in 1996, our analyses investigate medical care costs associated with cognitive impairment 1 to 2 years before an $\mathrm{AD}$ diagnosis. While an additional small number of respondents $(\mathrm{n}=23)$ received an $\mathrm{AD}$ diagnosis in 1999, we did not consider them prodromal cases for this analysis. Thus, our estimates apply only to costs 1 to 2 years before diagnosis and can be considered conservative for this reason.

Identification of older adults who developed $A D$. Every WHICAP subject completes neuropsychological testing at each assessment interval. Respondents who met criteria for $\mathrm{AD}$ were classified as either "prevalent" (subjects who met criteria for $\mathrm{AD}$ at their initial assessment) or "incident" (subjects who did not meet criteria for AD at their first visit but did so at a later visit). Although subjects were diagnosed by the research team at different times throughout 1997 to 1998, all subjects were assessed for medical care costs in 1996, the same 1-year period.

Medical expenditure data. We examined Medicare outpatient and ambulatory care [Part B] standard analytical files for 1996, obtained from the Health Care Financing Administration (HCFA), because these cover the domain of primary care. The ambulatory care file (also known as the "physician/supplier" file) covers all costs associated with physicians, other providers, clinical lab services provided in a physician's office, durable medical equipment, and related costs. The outpatient file covers all costs related to clinic services. ${ }^{18} \mathrm{We}$ obtained utilization and expenditure data for all Medicare enrollees in the three zipcodes that make up the WHICAP catchment area. We then matched WHICAP respondents to HCFA files by social security number and birth date and manually checked each match.

With use of Medicare data, 66.3\% of the cohort had at least one claim in either ambulatory care, outpatient, or inpatient files. The Medicare match rate was similar within cognitive status groups (nondemented, 65.7\%; prevalent $\mathrm{AD}, 63.6 \%$; prodromal $\mathrm{AD}, 75.3 \% ; p>0.05$ by $\chi^{2}$ ). If we consider Medicaid in addition to Medicare claims, the match rate was higher: $86.5 \%(1,221 / 1,411)$ of the non-AD group, $76.7 \%(198 / 258)$ of the prevalent $\mathrm{AD}$ group, and $89.1 \%$ (82/97) of the prodromal group $(p<0.01)$. Respondents in the prodromal group were significantly more likely to have claims using the combined Medicare and Medicaid data.

Respondents in Washington Heights-Inwood are likely to receive primary care in both hospital outpatient and ambulatory care settings. Hence, we computed a "primary care" composite, which was simply the sum over all encounters in these two files for each subject.

Medical conditions. Research physicians and trained research assistants elicited medical conditions (heart disease, hypertension, pulmonary disease, diabetes, arthritis, $\mathrm{PD}$, depression, or other disorders) from respondents or proxies. The number of conditions was summed to create a modified Charlson index. ${ }^{19}$ We established three groups $(0$, 1 , or $2+$ conditions), each representing about a third of the sample.

Analyses. Respondent-level utilization and expenditure indicators were derived by summing over Medicare encounters. For subjects who had a claim in one file (e.g., ambulatory care) but lacked claims in another (e.g., outpatient), we assigned the subject a zero value for the latter type of medical encounter. These subjects were clearly in the Medicare system, and absence of a claim in such cases can reasonably be construed as absence of a medical encounter. We also assigned a zero value to subjects without claims in any of the Medicare standard analytic files and who did not have Medicaid claims. This approach is reasonable because all subjects in the cohort were originally ascertained from Medicare enrollment files. We conducted analyses without the latter imputation, but as results were similar, we report only the imputed analysis.

For ambulatory and outpatient care in the cognitive status groups, we examined any use and mean and median expenditures in 1996, adapting the two-part model suggested by Duan et al. ${ }^{20}$ Because of skew in cost distributions, we used nonparametric tests (Mann-Whitney $U$, Kruskal-Wallis) to test whether median costs in groups defined by cognitive status were significantly different.

Finally, we used expenditure data from New York City (NYC) to estimate the aggregate US primary care cost of cognitive impairment in the period before $\mathrm{AD}$ diagnosis. To convert WHICAP expenditures into national figures, we reweighted mean costs by race-ethnicity group to match those of the NYC metropolitan area as a whole. We then converted these regional costs to national estimates using the adjusted average per capita cost (provided by HCFA), 
Table 1 Characteristics of WHICAP subjects with claims data, by dementia status, 1996

\begin{tabular}{lccc}
\hline & & Demented, \\
Characteristic & $\begin{array}{c}\text { Nondemented, } \\
\mathrm{n}=1,221\end{array}$ & $\begin{array}{c}\text { Prodromal } \\
\mathrm{n}=198,\end{array}$ & $\mathrm{n}=82$ \\
\hline Age in 1996, $\mathrm{y}^{*}$ & $77.3 \pm 5.9$ & $83.1 \pm 6.9$ & $82.4 \pm 6.7$ \\
Education, $\mathrm{y}^{*}$ & $8.7 \pm 4.6$ & $5.9 \pm 4.4$ & $7.6 \pm 4.6$ \\
Female, \% & 69.8 & 79.8 & 66.0 \\
Race-ethnicity, \%* & & & \\
$\quad$ White & 91.8 & 4.6 & 3.5 \\
$\quad$ Black & 77.8 & 15.8 & 6.4 \\
$\quad$ Hispanic & 75.9 & 18.4 & 5.6 \\
Co-morbid $\quad$ & & \\
$\quad$ conditions, \% & & & \\
0 & 21.5 & 16.2 & 19.5 \\
1 & 32.1 & 28.4 & 26.8 \\
$2+$ & 46.5 & 55.3 & 53.7 \\
\hline
\end{tabular}

Subjects were recruited in 1992 and survived through 1996. Subjects with "other" self-reported race $(n=7)$ were excluded from Race-ethnicity presentation. Counts of conditions were based on a modified Charlson index.

$* p<0.001, \dagger p<0.01$, by $\chi^{2}$ or one-way analysis of variance.

WHICAP $=$ Washington Heights-Inwood Columbia Aging Project.

with appropriate age- and sex-rescaling weights. Specifically, NYC costs were multiplied by the ratio of the retrospective US per capita cost to the NYC cost (Part B Aged rates: http://www.hcfa.gov/stats/hmorates/aapccflt.htm). We obtained the proportion of elderly people in the United States $\geq 75$ years old from the US Census $2000^{21}$ and used a range of $\mathrm{AD}$ prevalence and incidence established in recent meta-analyses. ${ }^{22,23}$ Because so few elderly people younger than 75 years became incident cases, no cost estimate is provided for this group. With these assumptions, we estimated the aggregate excess primary care cost (in 1996 dollars) associated with prodromal AD projected for the US population.

Results. Sociodemographic and vital status of WHICAP expenditure cohort. Table 1 presents features of the cognitive status groups in 1996. The groups differed significantly in age and education; prevalent $\mathrm{AD}$ cases were older and less educated. Prevalent $\mathrm{AD}$ cases were also more likely to be minority. The groups did not significantly differ in total number of medical conditions. The proportion of respondents with particular medical conditions in each of the cognitive status groups is also shown (additional material can be found on the Neurology Web site; go to www.neurology.org).

Medicare expenditures in 1996. The cognitive status groups did not significantly differ in the proportion of subjects with hospitalizations in 1996 (nondemented, 14.3\%; prevalent $\mathrm{AD}, 17.2 \%$; incident $\mathrm{AD}, 22.0 \%$ ). The groups did differ in primary care expenditures, as shown in table 2. One to 2 years before diagnosis, people who went on to develop $\mathrm{AD}$ were more likely to have an outpatient or ambulatory care visit ( 82.9 vs $71.7 \%$ in nondemented and
Table 2 Ambulatory and outpatient Medicare expenditures, WHICAP 1996, by cognitive status

\begin{tabular}{|c|c|c|c|}
\hline Sample & Nondemented & $\begin{array}{c}\text { Prodromal } \\
\text { AD }\end{array}$ & $\begin{array}{c}\text { Prevalent } \\
\text { AD }\end{array}$ \\
\hline Full sample, n & 1,221 & 82 & 198 \\
\hline Any primary care, $\%^{*}$ & 71.7 & 82.9 & 79.8 \\
\hline Primary care, median $\$ \ddagger$ & 587 & 1,480 & 943 \\
\hline Males, $\mathrm{n}$ & 382 & 30 & 42 \\
\hline Any primary care, $\% \dagger$ & 63.9 & 86.7 & 78.6 \\
\hline Primary care, median $\$ \ddagger$ & 336 & 1,738 & 1,206 \\
\hline Females, $\mathrm{n}$ & 839 & 52 & 156 \\
\hline Any primary care, $\%$ & 75.2 & 80.1 & 80.1 \\
\hline Primary care, median $\$^{*}$ & 662 & 1,389 & 891 \\
\hline Age $<75 \mathrm{y}, \mathrm{n}$ & 521 & 7 & 23 \\
\hline Any primary care, $\%$ & 68.3 & 75.0 & 82.6 \\
\hline Primary care, median $\$$ & 561 & 1,783 & 1,023 \\
\hline Age $\geq 75 \mathrm{y}, \mathrm{n}$ & 700 & 75 & 175 \\
\hline Any primary care, $\%$ & 74.2 & 84.0 & 79.4 \\
\hline Primary care, median $\$ \ddagger$ & 595 & 1,462 & 938 \\
\hline White, non-Hispanic, $\mathrm{n}$ & 321 & 13 & 14 \\
\hline Any primary care, $\%$ & 60.8 & 76.9 & 35.7 \\
\hline Primary care, median $\$$ & 287 & 1,498 & 0 \\
\hline Black, $\mathrm{n}$ & 399 & 30 & 63 \\
\hline Any primary care, $\%$ & 68.7 & 76.7 & 76.2 \\
\hline Primary care, median $\$^{*}$ & 498 & 1,353 & 902 \\
\hline Hispanic, $\mathrm{n}$ & 501 & 39 & 121 \\
\hline Any primary care, $\%$ & 81.1 & 89.7 & 86.8 \\
\hline Primary care, median $\$$ & 840 & 1,502 & 1,103 \\
\hline
\end{tabular}

Primary care includes costs in outpatient and ambulatory (Part B) files.
$* p<0.05, \dagger p<0.01, \ddagger p<0.001$ by $\chi^{2}$ (any primary care) or Mann-Whitney test (median $\$$ ) for comparison of non-AD and prodromal $\mathrm{AD}$ groups.

WHICAP $=$ Washington Heights-Inwood Columbia Aging Project.

$79.8 \%$ in prevalent $\mathrm{AD} ; p=0.01$ by $\chi^{2}$ ). Respondents who later received $\mathrm{AD}$ diagnoses were also likely to have higher primary care costs. Median costs in 1996 were $\$ 587$ for nondemented, $\$ 943$ for prevalent $\mathrm{AD}$, and $\$ 1,480$ for prodromal $\mathrm{AD}$ ( $p=0.001$ by Kruskal-Wallis test for all three groups, $p=0.001$ by Mann-Whitney $U$ test for nondemented vs prodromal AD).

Sex and expenditures. Separating total costs by sex shows that the greater cost in the prodromal $\mathrm{AD}$ group holds for both men and women but is considerably larger among men (see table 2). Comparing nondemented and prodromal $\mathrm{AD}$ groups, median costs were $\$ 336$ and $\$ 1,738$ for men $(p<$ $0.001)$ and $\$ 662$ and $\$ 1,389$ for women $(p<0.05)$.

Age and expenditures. Primary care costs were higher in the prodromal group compared with people who remained dementia-free, but this difference did not achieve significance in the young-old, defined here as people younger than 75 years (see table 2). Among elderly people 


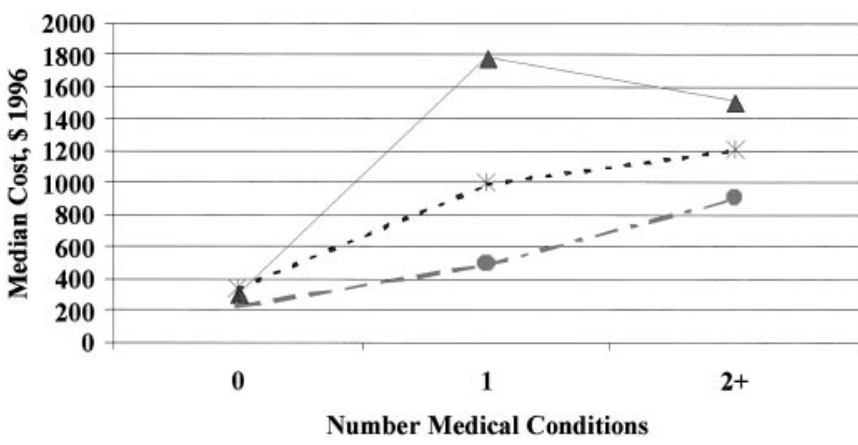

Figure 2. Median cost, 1996: AD status by number of comorbid conditions. Triangles $=$ prodromal $A D$; stars $=$ prevalent $A D$; circles $=$ no $A D$.

$\geq 75$ years old, the median primary care cost in the prodromal AD group was $\$ 1,462$ compared with $\$ 595$ in the group that remained free of dementia $(p<0.001)$.

Race-ethnicity and expenditures. In all three raceethnicity groups, prodromal $\mathrm{AD}$ was associated with increased primary care costs relative to respondents who never met criteria for $\mathrm{AD}$ (see table 2). Median costs for nondemented and prodromal AD groups were $\$ 287$ and $\$ 1,498$ among whites, $\$ 498$ and $\$ 1,353$ among blacks, and $\$ 840$ and $\$ 1,502$ among Hispanics. The small number of whites with prevalent AD ( $\mathrm{n}=14)$ were largely in nursing homes and accordingly had few Medicare charges for primary care (hence the $\$ 0$ median primary care charge).

Comorbid medical conditions and expenditures. Figure 2 plots primary care costs in the cognitive status groups by number of medical conditions. Prodromal AD was associated with increased median primary care costs for respondents who had one $(p=0.005)$ or two or more $(p=0.04)$ conditions. Within groups defined by the presence or absence of particular medical conditions, the prodromal $\mathrm{AD}$ group had higher primary care costs than the non-AD group (additional material can be found on the Neurology Web site; go to www.neurology.org). For example, for respondents with pulmonary disease, mean primary care costs were $\$ 2,198$ for the prodromal $\mathrm{AD}$ group and $\$ 1,969$ for the non-AD group.

Aggregate US costs of prodromal $A D$, elders $\geq 75$ years old. We developed estimates for the aggregate cost of prodromal $\mathrm{AD}$ in the period before diagnosis but restricted these estimates to people $\geq 75$ years old because, as noted earlier, few older adults younger than 75 years developed AD. Results are shown in table 3 . The mean primary care cost (US equivalent) for men with prodromal AD in 1996 was $\$ 2,532$, an excess of $\$ 1,167$ (or $85 \%$ ) over men who did not develop $\mathrm{AD}$. For women, the cost was $\$ 1,142$, an excess of $\$ 239$ (or $26 \%$ ) over women who did not develop $\mathrm{AD}$.

The US Census 2000 reported 6.1 million men and 10.5 million women $\geq 75$ years old and 1.2 million men and 3.0 million women were $\geq 85$ years old. ${ }^{18}$ To estimate the total cost of primary care for prodomal $\mathrm{AD}$, we assumed a prevalence rate of $6 \%$ in the 75 to 84 age group and $20 \%$ in people $\geq 85$ years old. ${ }^{22}$ We assumed an annual AD incidence of 1.1 to $1.8 \%$ for people aged 75 to 84 and 3 to $4 \%$ in people $\geq 85$ years old. ${ }^{22,23}$ With these assumptions, approximately 230,000 to 345,000 people $\geq 75$ years old develop $\mathrm{AD}$ each year and can be considered to have prodromal disease. Using the lower-end incidence estimate, total primary care costs for men with prodromal disease (estimated at $\$ 2,532$ per case from table 3 ) were $\$ 128.3$ million (age 75 to 84 ) and $\$ 72.9$ million (age $\geq 85$ ). If these men did not have prodromal $\mathrm{AD}$, total primary care costs (estimated at $\$ 1,365$ per case) would have been $\$ 69.2$ and $\$ 39.3$ million. The excess primary care expense attributable to prodromal $\mathrm{AD}$ is the difference, or $\$ 92.7$ million. Repeating this analysis for women, the excess primary care cost attributable to prodromal $\mathrm{AD}$ is $\$ 35.8$ million. The total increase in primary care cost associated with prodromal $\mathrm{AD}$ is $\$ 128.5$ million. With use of the higher incidence estimates, the increase in primary care costs associated with prodromal $\mathrm{AD}$ is $\$ 194.7$ million.

Discussion. Respondents identified as having AD for the first time in 1997 to 1998 were likely to have high primary care expenditures already in 1996, 1 to 2 years before their diagnosis. This finding is

Table 3 Medicare-based primary care costs of $A D$, aged $\geq 75$ years: Washington Heights $(n=955)$, New York City (NYC), and national cost estimates, 1996

\begin{tabular}{llcccc}
\hline Sex & \multicolumn{1}{c}{$\begin{array}{c}\text { Medicare primary } \\
\text { care cost, } \\
\text { status }\end{array}$} & WHICAP, $\$(\mathrm{n})$ & $\begin{array}{c}\text { Medicare primary } \\
\text { care cost, NYC, } \$^{*}\end{array}$ & $\begin{array}{c}\text { EAPCC/USPCC US } \\
\text { equivalent cost, } \$ \dagger\end{array}$ & $\begin{array}{c}\text { AD case in year prior to } \\
\text { diagnosis, } \$ \ddagger\end{array}$ \\
\hline Male & Prevalent AD & $2,967(35)$ & 1,972 & 1,309 & - \\
& Prodromal AD & $2,826(28)$ & 3,815 & 2,532 & $-1,167$ \\
Female & No AD & $1,790(203)$ & 2,056 & 1,365 & - \\
& Prevalent AD & $1,902(140)$ & 987 & 655 & 239 \\
& Prodromal AD & $1,854(47)$ & 1,720 & 1,142 & -
\end{tabular}

\footnotetext{
* The Washington Heights-Inwood Columbia Aging Project (WHICAP) sample is skewed toward blacks (33\%) and Hispanics (43\%) compared with whites $(24 \%)$. Cost estimates were reweighted to reflect race-ethnicity among elders aged $75+$ in the NYC metropolitan area as a whole, as derived from the Current Population Survey, March 2000 (blacks, 10\%; Hispanics, 10\%; whites, 80\%).

$\dagger \mathrm{AAPCC}=$ adjusted average per capita cost using age- and gender-rescaling weights. NYC costs were multiplied by (retrospective US per capita cost [USPCC] estimates/NYC estimate) using figures for Part B Aged. Available at: http://www.hcfa.gov/stats/hmorates/ aapccflt.htm.

$\ddagger$ Cost of prodromal case - cost of respondent without AD.
} 
strengthened by a number of features of our study design. First, expenditure data and diagnoses were obtained separately; thus, we were able to avoid the observation bias that has been identified for claimsbased studies. ${ }^{4}$ Second, our results were derived from a population-based study and hence avoid threats to generalizability associated with samples drawn from clinics or managed care organizations. Finally, through use of a neuropsychological test battery and medical and neurologic examination, we were able to separate $\mathrm{AD}$ from other forms of dementia.

Why should respondents have increased primary care expenditures in the period before an $\mathrm{AD}$ diagnosis? The increased cost does not appear to be a result of a greater number of comorbid conditions, at least when expressed as a simple count. When matched for number of comorbid conditions, people who went on to develop $\mathrm{AD}$ had higher primary care expenditures than people who never met criteria for $\mathrm{AD}$. A limitation of this approach is that it treats each disease equally when clearly some diseases lead to more encounters. More research on the co-occurrence of $\mathrm{AD}$ and other medical conditions will be required to clarify this issue. Increased expenditures in the absence of at least gross differences in medical status suggest that prodromal $\mathrm{AD}$ may itself increase the need for medical care. Also, increased median costs were evident across groups defined by race, age, and sex.

These high expenditures may be related to the diagnostic process; that is, families utilize medical services (primary care physician, neurologist, memory disorder clinic) as they attempt to determine what is wrong with an elder. It is also possible that high primary care expenditures are related to poorer post-treatment medical outcomes in people with early evidence of cognitive deficit who do not yet meet criteria for $\mathrm{AD}$. People who go on to receive $\mathrm{AD}$ diagnoses may be less able to adhere to treatment and medication regimens and may also fail to recognize medical symptoms early. The result may be more expensive primary care.

Additional research is required to clarify this question. Whereas the increased risk for mortality associated with $\mathrm{AD}$ is well established, ${ }^{24-26}$ people who die with $\mathrm{AD}$ do not appear to die of different causes than other people. The most frequent causes of death, established from death certificates or through multiple data sources (as in the National Mortality Followback Survey), do not distinguish people with and without AD. ${ }^{27}$ Increased primary care expenditures associated with prodromal $\mathrm{AD}$, then, may not be due to a particular medical profile, such as pneumonia or falls, but may instead reflect the general medical needs of people with increasing disability. In NYC, for example, physician evaluation is required for Medicaid approval of personal assistance care.

One potential limitation in this research is the match rate we obtained for Medicare data. The match rate in the WHICAP sample was $66.3 \%$, which is lower than that reported for older adults in other studies, such as the National Long-Term Care Survey. ${ }^{28}$ The WHICAP match rate should be considered in light of the predominantly minority (and immigrant) status of the cohort and its high Medicaid profile.

An unexpected result in this research was the lower use of Medicare-reimbursed primary care among women who ultimately developed AD. This result requires further investigation. It supports recent research showing disparities between older men and women in receipt of home care ${ }^{29}$ and suggests that women may be better advocates for a spouse's health than men.

Finally, our results suggest that primary care for people with prodromal $\mathrm{AD}$ is expensive. The aggregate excess annual Medicare-reimbursed primary care cost for this group, projected to the US population $\geq 75$ years old, is $\$ 128.9$ to $\$ 195.5$ million. Cost estimates used for this projection were drawn from a particular sample within one region of the United States. For this reason, we applied adjustments to make the sample representative of the racial-ethnic (and hence socioeconomic) distribution of the NYC metropolitan area as a whole and adjusted for this regional effect. The estimate must be considered approximate, as estimates of annual $\mathrm{AD}$ incidence and prevalence vary considerably. Still, the large excess primary care cost suggests that therapies able to delay the incidence of $\mathrm{AD}$ would have immediate economic importance. It is also likely that many other diseases are associated with excess primary care costs in the prodromal period. These costs need to be captured if we are to understand the total economic impact of disease.

\section{References}

1. Leibson C, Owens T, O'Brien P, et al. Use of physician and acute care services by persons with and without Alzheimer's disease: a population-based comparison. J Am Geriatr Soc 1999;47:864-869.

2. Gutterman E, Markowitz JS, Lewis B, et al. Cost of Alzheimer's disease and related dementia in managed-Medicare. J Am Geriatr Soc 1999;47:1065-1071.

3. Richards KM, Shepard MD, Crismon ML, et al. Medical ser vices utilization and charge comparisons between elderly patients with and without Alzheimer's disease in a managed care organization. Clin Ther 2000;22:775-791.

4. Newcomer R, Clay T, Luxenberg JS, et al. Misclassification and selection bias when identifying Alzheimer's disease solely from Medicare claims records. J Am Geriatr Soc 1999;47:215219.

5. Hux MJ, O'Brien BJ, Iskedjian M, et al. Relation between severity of Alzheimer's disease and costs of caring. Can Med Assoc J 1998;159:457-465.

6. Andersen CK, Søgaard J, Hansen E, et al. The cost of dementia in Denmark: the Odense study. Dement Geriatr Cogn Disord 1999;10:295-304.

7. Albert SM, Sano M, Bell K, et al. Hourly care received by people with Alzheimer's disease: results from an urban, community survey. Gerontologist 1998;38:704-714.

8. Albert SM, Costa R, Merchant C, et al. Hospitalization and Alzheimer's disease: results from a community-based study. J Gerontol Med Sci 1999;54A:M267-M271.

9. Martin BC, Ricci JF, Kotzan JA, et al. The net cost of Alzheimer disease and related dementia: a population-based study of Georgia Medicaid recipients. Alzheimer Dis 2000;14:151-159. 
10. Weiler PG, Lubben JE, Chi I. Cognitive impairment and hospital use. Am J Public Health 1991;81:1153-1157.

11. Ganguli M, Seaberg E, Belle S, et al. Cognitive impairment and the use of health services in an elderly rural population: the MoVIES Project. J Am Geriatr Soc 1993;41:1065-1070.

12. Coughlin TA, Liu K. Health care costs of older persons with cognitive impairment. Gerontologist 1989;29:173-182.

13. Welch HG, Walsh JS, Larson EB. The cost of institutional care in Alzheimer's disease: nursing home and hospital use in a prospective cohort. J Am Geriatr Soc 1992;40:221-224.

14. Weiner M, Powe NR, Weller WE, et al. Alzheimer's disease under managed care: implications from Medicare utilization and expenditure patterns. J Am Geriatr Soc 1998;46:762-770.

15. Gurland BJ, Wilder DE, Lantigua R, et al. Differences in rates of dementia in ethnocultural groups. In: Martin LG, Soldo BJ, eds. Racial and ethnic differences in the health of older Americans. Washington, DC: National Academy Press, 1997:233-269.

16. Gurland BJ, Wilder DE, Cross P, et al. Relative rates of dementia by multiple case definitions, over two prevalence periods, in three cultural groups. Am J Geriatr Psychiatry 1995;3: $6-20$.

17. Tang M-X, Stern Y, Marder K, et al. The APOE-€ 4 allele and the risk of Alzheimer disease among African-Americans, whites, and Hispanics. JAMA 1998;279:751-755.

18. Health Care Financing Administration. Data compendium. US Department of Health and Human Services, 1998. Available at: http://www.hcfa.goc/stats/98datacmp.pdf.

19. Charlson ME, Pompei P, Ales KL, et al. A new method of classifying prognostic morbidity in longitudinal studies: development and validation. J Chronic Dis 1987;40:373-382.
20. Duan N, Manning WG, Morris CN, et al. A comparison of alternative models for the demand for medical care. J Bus Econ Stat 1983;1:115-126.

21. US Census Bureau. Brief. The 65 years and over population, C2KBR/01-10. Washington, DC, 2001 and 2000.

22. Brookmeyer R, Gray S, Kawas C. Projections of Alzheimer's disease in the United States and the public health impact of delaying disease onset. Am J Public Health 1998;88:13371342.

23. Gao S, Hendrie H, Hall KS, et al. The relationship between age, sex, and the incidence of dementia and Alzheimer's disease. Arch Gen Psychiatry 1998;55:809-815.

24. Katzman T, Hill LR, Yu ES, et al. The malignancy of dementia: predictors of mortality in clinically diagnosed dementia in a population survey of Shanghai, China. Arch Neurol 1994;51: $1220-1225$.

25. Kelman HR, Thomas C, Kennedy GJ, et al. Cognitive impairment and mortality in older community residents. Am J Public Health 1994;84:1255-1260.

26. Witthaus E, Ott A, Barendregt JJ, et al. Burden of mortality and morbidity from dementia. Alzheimer Dis 1999;13:176181.

27. Lanska DJ. Dementia mortality in the United States: results of the 1986 National Mortality Followback Survey. Neurology 1998;50:362-367.

28. Taylor DH, Sloan FA. How much do persons with Alzheimer's disease cost Medicare? J Am Geriatr Soc 2000;48:639-646.

29. Katz SJ, Kabeto M, Langa KM. Gender disparities in the receipt of home care for elderly people with disability in the United States. JAMA 2000;284:3022-3027.

\section{ACTIVATE YOUR ONLINE SUBSCRIPTION}

At www.neurology.org, subscribers can now access the full text of the current issue of Neurology and back issues to 1999. Select the "Login instructions" link that is provided on the Help screen. Here you will be guided through a step-by-step activation process.

Neurology online offers:

- Access to journal content in both Adobe Acrobat PDF or HTML formats

- Links to PubMed

- Extensive search capabilities

- Complete online Information for Authors

- Examinations on designated articles for CME credit

- Access to in-depth supplementary scientific data 


\section{Neurology}

Primary care expenditures before the onset of Alzheimer's disease

S. M. Albert, S. Glied, H. Andrews, et al.

Neurology 2002;59;573-578

DOI 10.1212/WNL.59.4.573

This information is current as of August 27, 2002

\section{Updated Information \&}

Services

Supplementary Material

References

Citations

Subspecialty Collections

Permissions \& Licensing

Reprints including high resolution figures, can be found at:

http://www.neurology.org/content/59/4/573.full.html

Supplementary material can be found at:

http://www.neurology.org/content/suppl/2002/08/19/59.4.573.DC1

This article cites 24 articles, 4 of which you can access for free at: http://www.neurology.org/content/59/4/573.full.html\#\#ref-list-1

This article has been cited by 3 HighWire-hosted articles:

http://www.neurology.org/content/59/4/573.full.html\#\#otherarticles

This article, along with others on similar topics, appears in the following collection(s):

All Cognitive Disorders/Dementia

http://www.neurology.org//cgi/collection/all_cognitive_disorders_dementia

All Health Services Research

http://www.neurology.org//cgi/collection/all_health_services_research

Alzheimer's disease

http://www.neurology.org//cgi/collection/alzheimers_disease

Cognitive aging

http://www.neurology.org//cgi/collection/cognitive_aging

Cost effectiveness/economic

http://www.neurology.org//cgi/collection/cost_effectiveness_economic_

Information about reproducing this article in parts (figures,tables) or in its entirety can be found online at:

http://www.neurology.org/misc/about.xhtml\#permissions

Information about ordering reprints can be found online:

http://www.neurology.org/misc/addir.xhtml\#reprintsus

Neurology ${ }^{\circledR}$ is the official journal of the American Academy of Neurology. Published continuously since 1951, it is now a weekly with 48 issues per year. Copyright . All rights reserved. Print ISSN: 0028-3878. Online ISSN: 1526-632X.

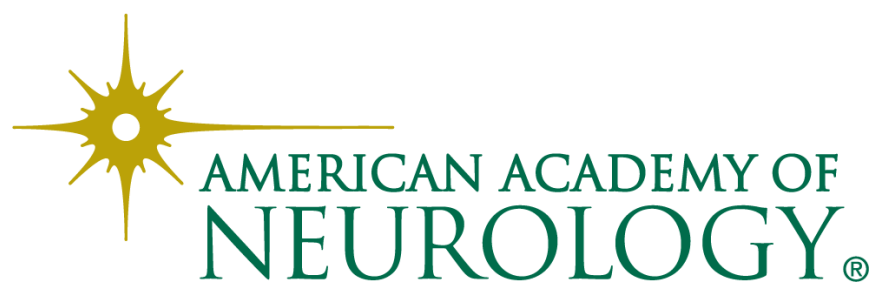

